\title{
Accelerated hand bone mineral density loss is associated with progressive joint damage in hands and feet in recent-onset rheumatoid arthritis
}

\author{
Melek Güler-Yüksel¹, Naomi B Klarenbeek1, Yvonne PM Goekoop-Ruiterman', Jeska K de Vries-Bouwstra2, \\ Sjoerd M van der Kooij', Andreas H Gerards ${ }^{3}$, H Karel Ronday4, Tom WJ Huizinga', Ben AC Dijkmans 2,5, \\ Cornelia F Allaart ${ }^{1}$ and Willem F Lems 2,5
}

\begin{abstract}
Introduction: To investigate whether accelerated hand bone mineral density (BMD) loss is associated with progressive joint damage in hands and feet in the first year of rheumatoid arthritis (RA) and whether it is an independent predictor of subsequent progressive total joint damage after 4 years.
\end{abstract}

Methods: In 256 recent-onset RA patients, baseline and 1-year hand BMD was measured in metacarpals 2-4 by digital $X$-ray radiogrammetry. Joint damage in hands and feet were scored in random order according to the Sharp-van der Heijde method at baseline and yearly up to 4 years.

Results: $68 \%$ of the patients had accelerated hand BMD loss $\left(>-0.003 \mathrm{~g} / \mathrm{cm}^{2}\right)$ in the first year of RA. Hand BMD loss was associated with progressive joint damage after 1 year both in hands and feet with odds ratios (OR) (95\% confidence intervals [CI]) of 5.3 (1.3-20.9) and 3.1 (1.0-9.7). In univariate analysis, hand BMD loss in the first year was a predictor of subsequent progressive total joint damage after 4 years with an OR $(95 \% \mathrm{Cl})$ of 3.1 (1.3-7.6). Multivariate analysis showed that only progressive joint damage in the first year and anti-citrullinated protein antibody positivity were independent predictors of long-term progressive joint damage.

Conclusions: In the first year of RA, accelerated hand BMD loss is associated with progressive joint damage in both hands and feet. Hand BMD loss in the first year of recent-onset RA predicts subsequent progressive total joint damage, however not independent of progressive joint damage in the first year.

\section{Introduction}

Bone damage in rheumatoid arthritis (RA) includes joint damage and accelerated bone mineral density (BMD) loss [1]. Joint damage is provoked by an increased osteoclast and decreased osteoblast activation, leading to erosive damage, and by proteolytic pathways, leading to cartilage degradation. This is all mostly regulated by TNF- $\alpha$, IL-1, IL-6, IL-17 and receptor activator of nuclear factor kappa B ligand (RANKL) [2-4]. It is believed that BMD loss, both localized and generalized, is also primarily the effect of increased osteoclast activity in RA [5]. In particular, bones in the proximity of inflamed joints are susceptible

* Correspondence: m.yuksel@lumc.nl

1 Department of Rheumatology, Leiden University Medical Center, Albinusdreef 2, 2333 ZA, Leiden, The Netherlands

Full list of author information is available at the end of the article to BMD loss due to inflammation [6]. Furthermore, localized hand BMD loss occurs in an early phase of RA [7] and even in pre-RA undifferentiated arthritis [8], and might precede erosive damage on X-ray $[9,10]$.

Dual energy X-ray absorptiometry (DEXA) is the gold standard for measuring BMD. Digital X-ray radiogrammetry (DXR) was developed as a method of radiogrammetry to estimate BMD in the metacarpals using standard hand radiographs [11]. BMD measured by DXR is highly correlated with DEXA measurements and DXR has a high precision for detecting changes in BMD $[11,12]$. Various clinical studies showed the association between hand BMD loss measured by DXR and RA severity, including disease activity, functional impairment and joint destruction [6,13-22]. Two clinical studies, one of them a pilot study, showed the potential value of BMD 
loss in hands measured by DXR to predict radiographic joint damage in hands $[23,24]$. However, to date, no data are available on the association between hand BMD loss and progressive joint damage in hands and feet and on the value of hand BMD loss as predictor of joint destruction in recent-onset RA patients who are treated intensively with disease modifying anti-rheumatic drugs (DMARDs) and TNF- $\alpha$ inhibitors in a tight control setting. We examined the association between accelerated hand BMD loss and progressive joint damage in hands and feet during the first year of recent-onset active RA to see whether both types of bone damage have common pathways in their pathogenesis, and we investigated whether accelerated hand BMD loss in the first year of RA was an independent predictor of subsequent progressive joint damage after four years in patients who are treated in a tight control setting.

\section{Materials and methods Patients}

All measures were performed in the setting of the Behandel Strategieën (BeSt) study [25]. Patients aged 18 years and older, who met the definition of RA as defined by the American College of Rheumatology (ACR) 1987 revised criteria, with symptom duration of less than two years and active disease with 6 or more of 66 swollen joints and 6 or more of 68 tender joints and either an erythrocyte sedimentation rate (ESR) of $28 \mathrm{~mm} /$ hour or more or a visual analogue scale (VAS) global health of $20 \mathrm{~mm}$ or more, and who were DMARD naïve, were included in the trial from April 2000 to August 2002. Exclusion criteria have been reported previously [25]. Of the 508 patients, 236 were excluded from this study predominantly due to switch from analogue to digital radiographs. The other 272 patients had analogue radiographs at both baseline and after one year and were eligible for this study. The baseline and/or one year follow-up analogue radiographs of 16 patients could not be analysed by DXR due to underexposed images (13 patients) or improper positioning of the hands (3 patients). Hence, 256 patients were included in the current study.

\section{Study design}

The BeSt study was conducted by rheumatologists participating in the Foundation for Applied Rheumatology Research, in 18 peripheral and 2 university hospitals in the western part of the Netherlands. The medical ethics committee at each participating center approved the study protocol and all patients gave written informed consent prior to participation in the study.

After inclusion, patients were randomized to be treated according to one of four treatment strategies: sequential monotherapy starting with methotrexate (MTX); step-up combination therapy also starting with MTX; initial combination therapy with quickly tapered high-dose prednisone, MTX and sulphasalazine, or initial combination therapy with infliximab and MTX. For all groups, the protocol described a number of subsequent treatment steps for patients whose response to therapy was insufficient, based on the disease activity score (DAS) in 44 joints of more than 2.4. The treatment protocol and the effect of the different treatment strategies on hand BMD loss after one and two years are described earlier in detail $[6,25]$.

Concomitant treatment with non-steroidal anti-inflammatory drugs and intra-articular corticosteroids were permitted but not parenteral corticosteroids. In case of calcium intake of less than $1,000 \mathrm{mg} /$ day and serum vitamin D level below the local reference value at baseline, suppletion of 500 to $1,000 \mathrm{mg} /$ day calcium and $400 \mathrm{IE} /$ day vitamin $\mathrm{D}$ (colecalciferol), respectively, was advised. Antiresorptive therapy with oral alendronate, $10 \mathrm{mg} /$ day or $70 \mathrm{mg} /$ week, or risedronate, $5 \mathrm{mg} /$ day or $35 \mathrm{mg} /$ week, was advised if the BMD measurement at baseline showed at a T-score -2.5 standard deviations (SD) or less in the spine and/or hip in non-corticosteroid users or a T-score -1 SD or less in corticosteroids users (ACR recommendations) [6].

\section{Hand BMD measurements}

Analogue radiographs of both hands in the posterioranterior view were digitized by a high-resolution 300 DPI scanner (Canon Vidar VXR-12 plus, Amstelveen, NorthHolland, The Netherlands) and analysed under blind conditions using the DXR-online (Pronosco X-posure system, Sectra, Sweden). According to the manufacturer, there is a very good agreement between BMD measured by DXR on original analogue radiographs and on digitalized versions. Patients who switched from analogue to digital radiographs were excluded due to lack of comparability between the different imaging devices.

DXR is a computerized version of the traditional technique of radiogrammetry originally proposed by Barnett and Nordin [26]. The digitized hand radiograph is subjected to a number of image processing algorithms to measure the cortical thickness of three regions of interest around the narrowest part of the second, third and fourth metacarpal bones [11]. A mean surrogate BMD, based on the mean volume per area, was calculated in $\mathrm{g} / \mathrm{cm}^{2}$ with correction for the estimated porosity. Both hands were measured and the mean was used for the analyses.

Hand BMD loss after one year was categorized in two groups using the cut-off of $-0.003 \mathrm{~g} / \mathrm{cm}^{2} /$ year, equal to the upper limit of normal BMD loss in the metacarpals according to specifications by the manufacturer. 


\section{Radiographic assessment of progressive joint damage}

Radiographic progression of joint damage in hands and feet at baseline and after one to four years were independently scored by two readers, blinded for patient characteristics, treatment group and time order, using the Sharp-van der Heijde score (SHS) [27]. The inter-class correlation coefficient between the readers was 0.98 . The mean score of the two observers were used for the analyses.

Progressive joint damage in the first year was defined as an increase in total SHS of 5 units or more at year one compared with baseline. In subanalyses, progressive joint damage in hands was defined as delta SHS 0 to 1 year 5 units or more, whereas progressive joint damage in feet was defined as delta SHS 0 to 1 year 3 units or more, due to a 0.6 times lower maximum score in feet than in hands. Subsequent progressive total joint damage in hands and feet was defined as delta SHS 1 to 4 years 5 units or more.

\section{Demographic and clinical variables}

The following variables were collected at baseline: age; sex; and symptom duration. At baseline and after one year the following variables were collected: postmenopausal status; body mass index (BMI); DAS; based on the number of swollen joints and the Ritchie articular index (RAI) for pain in tender joints; the VAS for patient's global assessment of disease activity (0 to $100 \mathrm{~mm}$ ); ESR; C-reactive protein (CRP); serum IgM rheumatoid factor (RF), defined as positive or negative according to locally applied assays and cut-off units; and functional disability by the Dutch validated health assessment questionnaire (HAQ). The presence of anti-citrullinated protein antibodies (ACPA) was determined from serum samples obtained at baseline or during follow up. The presence or absence of ACPA is a stable characteristic [28].

\section{Statistical analyses}

All analyses were performed in an intention-to-treat method using all available data.

To determine the associations between hand BMD loss and progressive joint damage in hands and feet after one year, multivariate logistic regression analyses were performed adjusted for age, gender, postmenopausal status, BMI, HAQ, baseline SHS, treatment group, and the use of intra-articular steroids and antiresorptive drugs (bisphosphonates, vitamin D and calcium supplements and hormone replacement therapy (HRT)).

The sensitivity, specificity, and positive and negative predictive value of hand BMD loss with regard to total progressive joint damage in the first year were calculated. Various baseline demographic and disease-related factors and one-year follow-up disease-related factors were analysed regarding prediction of subsequent progressive total joint damage after four years by univariate logistic regres- sion analyses adjusted for age, gender, postmenopausal status, BMI and $\mathrm{HAQ}$, and additionally adjusted for the treatment group and use of antiresorptive drugs and intra-articular steroids during the first year follow-up in case of one-year follow up variables. The following factors were analysed: baseline demographic factors (gender, age $\geq 50$ years, postmenopausal status and BMI $\geq 25 \mathrm{~kg} /$ $\mathrm{m}^{2}$ ), baseline disease-related factors (symptom duration $\geq$ 6 months, presence ACPA and RF, number of swollen joints $\geq 10$, RAI $\geq 10$, ESR $\geq 30 \mathrm{~mm} / \mathrm{hr}, \mathrm{CRP} \geq 10 \mathrm{mg} / \mathrm{L}$, HAQ $\geq 1.057$ units [29] and SHS $\geq 1$ unit) and one-year follow-up disease-related factors (high area under the curve (AUC) of number of swollen joints, RAI, ESR and CRP and delta HAQ $\leq-0.22$ units [30], total SHS $\geq 5$ units and hand BMD loss $>-0.003 \mathrm{~g} / \mathrm{cm}^{2}$ ). Both significant (pvalue $<0.05)$ and borderline significant $(0.05<P<0.10)$ predictors derived by these univariate analyses were entered in multiple multivariate logistic regression analyses to determine the independent predictors of subsequent progressive joint damage.

\section{Results}

\section{Patient characteristics}

The baseline characteristics of the 256 patients included in the study and 252 patients excluded are shown in Table 1. Patients included had shorter disease duration, were less frequently ACPA positive and had less damage in the feet, especially less cartilage degradation, compared with the non-included patients. With regard to randomization into the four treatment groups by age, sex, RF, DAS, ESR level, CRP level, HAQ score, hand SHS and BMD (obtained in 107 patients at baseline who were excluded from this study), there were no significant differences between patients who were enrolled in this study and who were not.

Of the study population, $65 \%$ were females, $66 \%$ of them postmenopausal, and the mean age was 54 years. At baseline the patients had a median symptom duration of 24 weeks and mean (SD) DAS of 4.4 (0.9). RF was positive in $62 \%$ of the patients and $70 \%$ had at least one erosion in hands and feet.

\section{Changes in hand BMD and joint damage in hands and feet in the first year}

The median (interquartile range (IQR)) hand BMD change was, in absolute value, $-0.0088 \mathrm{~g} / \mathrm{cm}^{2}(-0.021$ to $0.0005)$ and in percentage of baseline BMD $-1.4 \%(-3.8 \%$ to $-0.1 \%$ ) after one year. On the individual level, $68 \%$ of patients had accelerated hand BMD loss of more than $0.003 \mathrm{~g} / \mathrm{cm}^{2}$, from now on called hand BMD loss. The mean (SD) progression of total SHS in hands and feet, and SHS in hands and feet separately was 3.0 (11.3), 1.9 (7.0) and 1.1 (5.0), respectively. After one year 18\%, 12\% and $11 \%$ of the patients had progressive total joint dam- 
Table 1: Baseline demographic and disease characteristics from patients from the BeSt cohort who are included and not included in this study

\begin{tabular}{|c|c|c|c|}
\hline Demographic variables & $\begin{array}{l}\text { Patients included in study } \\
\qquad(\mathrm{n}=256)\end{array}$ & $\begin{array}{l}\text { Patients not included in study } \\
\qquad(\mathrm{n}=252)\end{array}$ & $P$ value \\
\hline Age, years ${ }^{\dagger}$ & $54(14)$ & $54(13)$ & 0.941 \\
\hline Women, \% & 65 & 70 & 0.208 \\
\hline Postmenopausal, $\%$ & 66 & 68 & 0.817 \\
\hline $\begin{array}{l}\text { Randomization between the } \\
\text { treatment groups, } \%\end{array}$ & $\begin{array}{l}\text { Sequential monotherapy: } 25 \\
\text { Step-up therapy: } 23 \\
\text { Initial combi therapy with } \\
\text { prednisone: } 27 \\
\text { Initial combi therapy with } \\
\text { infliximab: } 26\end{array}$ & $\begin{array}{l}\text { Sequential monotherapy: } 25 \\
\text { Step-up therapy: } 25 \\
\text { Initial combi therapy with } \\
\text { prednisone: } 25 \\
\text { Initial combi therapy with } \\
\text { infliximab: } 25\end{array}$ & 0.921 \\
\hline \multicolumn{4}{|l|}{ Disease related variables } \\
\hline Symptom duration, weeks ${ }^{\ddagger}$ & $24(14-53)$ & $23(13-53)$ & 0.929 \\
\hline Disease duration, weeks ${ }^{\ddagger}$ & $2(1-5)$ & $3(1-5)$ & 0.011 \\
\hline $\begin{array}{l}\text { ACPA positive, } \%, n=247 \text { (not all } \\
\text { baseline) }\end{array}$ & 54 & 70 & 0.000 \\
\hline RF positive, $\%$ & 62 & 68 & 0.175 \\
\hline DAS $^{+}$ & $4.4(0.9)$ & $4.4(0.9)$ & 0.529 \\
\hline $\mathrm{ESR}^{\ddagger}$ & $37(19-54)$ & $36(19-57)$ & 0.781 \\
\hline CRP $\neq$ & $20(9-58)$ & $26(10-55)$ & 0.272 \\
\hline HAQ score, 0-3 scale ${ }^{\dagger}$ & $1.4(0.6)$ & $1.4(0.7)$ & 0.276 \\
\hline Total SHS, 0-448 scale ${ }^{\ddagger},+n=248$ & $5.9(8.2) / 2.5(0.5-8.5)$ & $8.7(12.7) / 4.3(1.0-11.0)$ & $0.024^{*}$ \\
\hline Erosion score, $0-280$ scale $^{\ddagger}, \dagger$ & $2.8(4.7) / 1(0.0-3.5)$ & $3.9(6.2) / 1.5(0.0-5.0)$ & $0.011^{*}$ \\
\hline JSN score, 0-168 scale f $^{\ddagger}$ & $3.0(4.8) / 1.0(0.0-4.1)$ & $4.8(7.7) / 2.0(0.0-5.6)$ & $0.041^{*}$ \\
\hline Total SHS hands, 0-280 scale ${ }^{\ddagger},+$ & $3.0(4.8) / 1.0(0.0-3.5)$ & $4.6(8.4) / 1.0(0.0-5.0)$ & $0.217^{*}$ \\
\hline Erosion score hands, 0-160 scale ${ }^{\ddagger, \dagger}$ & $0.9(1.8) / 0.0(0.0-1.0)$ & $1.4(3.1) / 0.5(0.0-1.0)$ & $0.112^{*}$ \\
\hline JSN score hands, 0-120 scale ${ }^{\ddagger, \dagger}$ & $2.1(3.9) / 0.0(0.0-3.0)$ & $3.1(6.0) / 0.50(0.0-3.6)$ & $0.247^{*}$ \\
\hline Total SHS feet, 0-168 scale ${ }^{\ddagger}, \dagger$ & $2.8(5.4) / 0.5(0.0-3.0)$ & $4.1(7.2) / 1.5(0.0-4.5)$ & $0.011 *$ \\
\hline Erosion score feet, 0-120 scale ${ }^{\ddagger}, \dagger$ & $1.9(3.9) / 0.5(0.0-2.0)$ & $2.5(4.6) / 0.5(0.0-2.5)$ & $0.123^{*}$ \\
\hline JSN score feet, 0-48 scale ${ }^{\ddagger},+$ & $0.9(2.0) / 0.0(0.0-1.0)$ & $1.7(3.4) / 0.0(0.0-2.0)$ & $0.013^{*}$ \\
\hline Presence erosive damage $\geq 1$ unit, & 70 & 74 & 0.321 \\
\hline$\% n=248$ & 28 & 34 & 0.166 \\
\hline $\begin{array}{l}\text { Presence erosive damage hands } \geq 1 \\
\text { unit, } \%\end{array}$ & 40 & 46 & 0.205 \\
\hline \multicolumn{4}{|l|}{$\begin{array}{l}\text { Presence erosive damage feet } \geq 1 \\
\text { unit, } \%\end{array}$} \\
\hline Hand BMD $\left(\mathrm{g} / \mathrm{cm}^{2}\right)^{\dagger}$ & $0.59(0.08)$ & $0.59(0.09) n=107$ & 0.870 \\
\hline
\end{tabular}

†Mean (standard deviation); $\neq$ median (interquartile range); ${ }^{*} P$ values derived from non-parametric tests.

ACPA, anti-citrullinated protein antibodies; BMI, body mass index; CRP, C-reactive protein; DAS, disease activity score; ESR, erythrocyte sedimentation rate; $\mathrm{HAQ}$, health assessment questionnaire; JSN, joint space narrowing; RF, rheumatoid factor; SHS, Sharp-van der Heijde score. 
age of 5 units or more, hand joint damage 5 units or more and feet joint damage of 3 units or more, respectively.

In patients with hand BMD loss the mean (SD) progression of total SHS after one year was 4.0 (13.6) compared with 1.1 (2.6) in patients without hand BMD loss $(P=$ 0.036 derived by non-parametric test). Hand BMD loss after one year was significantly associated with higher progression rates both in hands $(2.5(8.4)$ versus 0.8 (1.7), $P=0.033$ ) and feet (1.4 (5.9) versus 0.4 (1.5), $P=0.047$ ). The cumulative probability plots of changes in total SHS and changes in hands and feet SHS separately after one year in patients with and without hand BMD loss are shown in Figure 1. Multivariate logistic regression analyses adjusted for possible confounders were performed to study the independent associations between hand BMD loss and progressive total joint damage in hands and feet. Progressive total joint damage in hands and feet after one year was independently associated with hand BMD loss with an odds ratio (OR) (95\% confidence interval (CI)) of 10.6 (2.6 to $42.7 ; P=0.001$ ). In separate analyses, hand BMD loss was associated with progressive joint damage in both hands and feet after one year, although more strongly in hands (OR (95\% CI) 5.3 (1.3 to 20.9)) than in feet (3.1 (1.0 to 9.7)). Both erosion and joint space narrowing (JSN) score in hands and feet contributed equally to the association with hand BMD loss (data not shown).

\section{Sensitivity, specificity and predictive value of hand BMD loss in the first year}

The sensitivity of hand BMD loss for detecting progressive total joint damage after one year was 39 of $45(87 \%)$ and the specificity 74 of 203 (36\%). The positive predictive value, the probability of the presence of progressive joint damage when hand BMD loss is present, was 39 of $168(23 \%)$, whereas the negative predictive value, the probability of absence of progressive joint damage when hand BMD loss is absent, was 74 of 80 (93\%).

\section{Predictors of subsequent progressive radiographic damage after four years}

The mean (SD) cumulative progression of total SHS in hands and feet was 3.0 (11.3), 4.9 (14.5), 5.8 (16.7) and 6.6 (13.3) after one to four years compared with baseline. After one to four years, $18 \%, 26 \%, 27 \%$ and $30 \%$ of the patients, respectively, had progressive total joint damage of 5 units or more. The association between hand BMD loss in the first year and progressive total joint damage remained over time up to four years (Figure 2).

The mean (SD) progression of total SHS was 2.9 (7.6) after four years compared with year one and $14 \%$ of the patients had progressive total joint damage of 5 units or more after four years compared with year one. To investigate whether hand BMD loss in the first year could predict long-term damage progression, univariate logistic regression analyses were performed with subsequent progressive total joint damage after four years of 5 units or more compared with year one as dependent variable and various potential baseline and one year follow-up predictors as independent variables adjusted for possible confounders (Table 2). Of the baseline variables, the presence of ACPA, RF and joint damage at baseline were significant predictors of subsequent progressive total joint damage after four years. Of the one-year follow-up variables, a high AUC of ESR and CRP, progressive total joint damage of 5 units or more and hand BMD loss were significant predictors of subsequent progressive joint damage after four years. The association of hand BMD loss with subsequent progressive joint damage was less strong (OR (95\% CI) 3.1 (1.3 to 7.6)) than the association with progressive joint damage in the first year (OR $(95 \% \mathrm{CI})$ 30.7 (9.4 to 100)).

Multiple multivariate regression analyses were performed to investigate the predictive ability of different factors and the mutual interaction between them. In the first multivariate model, all (borderline) significant predictors from the univariate analyses were entered, adjusted for possible confounders (Table 3). The presence of ACPA was an independent predictor of progressive joint damage with an OR (95\% CI) of 3.1 (1.4 to 6.1). Progressive joint damage in the first year was a strong and independent predictor of subsequent progressive joint damage with an OR (95\% CI) of 27.1 (10.9 to 67.4). Hand BMD loss in the first year with the diagnosis of RA was not an independent predictor anymore $(P=0.688)$. The adjusted $\mathrm{R}^{2}$, estimating the proportion of variance in progressive joint damage that is explained by the predictors, was 0.53 .

In the second multivariate model all (borderline) significant predictors from the univariate analyses were entered, except progressive joint damage in the first year, adjusted for possible confounders (Table 4). Hand BMD loss in the first year was a predictor of subsequent progressive joint damage independent of the presence of auto-antibodies, joint damage at baseline and high AUC of ESR and CRP with an OR (95\% CI) of 3.0 (1.1 to 8.8). The adjusted $\mathrm{R}^{2}$ was considerably lower at 0.29 .

To explore further the usefulness of progressive joint damage in the first year as a predictor of subsequent progressive damage, joint damage progression in the first year was divided in to four groups: no progression (SHS $\leq$ 0 unit, the reference group), dubious progression $(0<$ SHS $<5$ units $)$, moderate progression $(5 \leq \mathrm{SHS}<10$ units) and high progression (SHS $\geq 10$ units). They were then entered in a third multivariate regression analysis together with all (borderline) significant predictors from the univariate analyses and possible confounders. This analysis showed that even dubious progressive joint damage was an independent predictor of subsequent progres- 


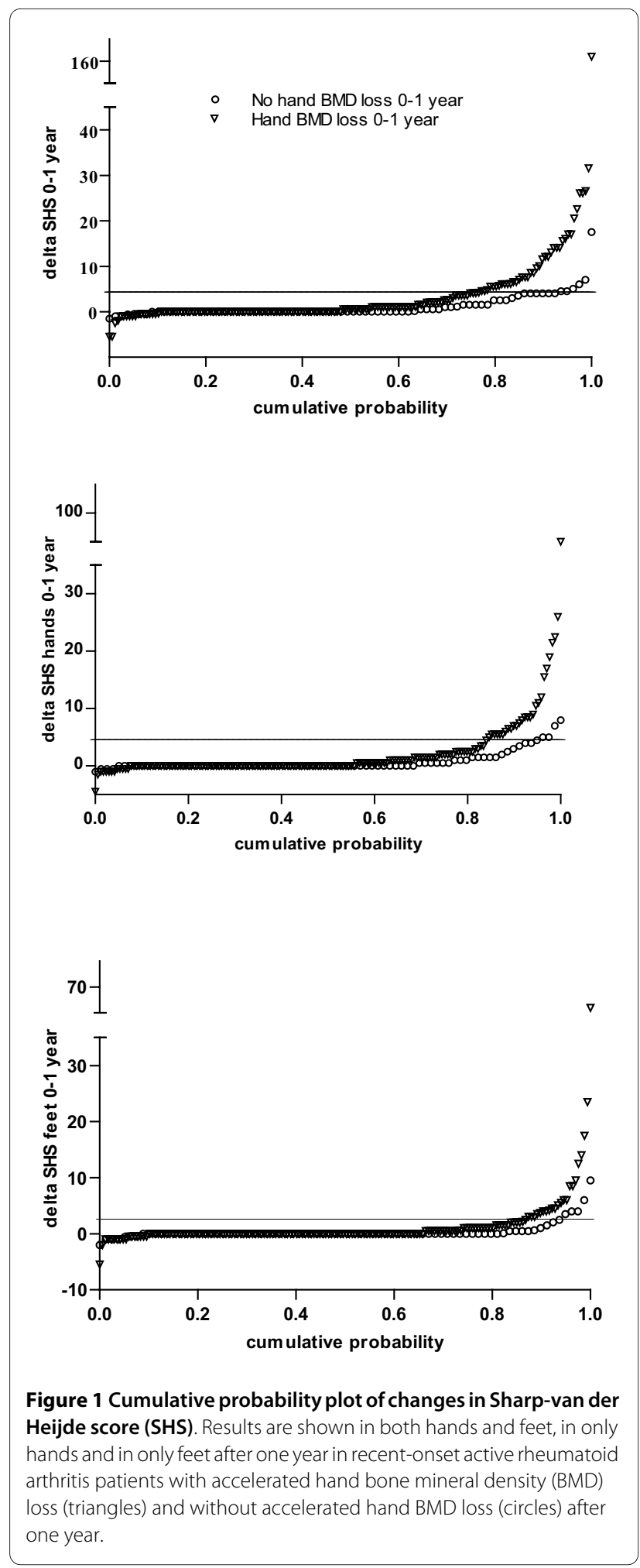

sive joint damage with an OR ( $95 \%$ CI) of 5.5 (1.3 to 24) and that the ORs (95\% CIs) were considerably higher when the progressive joint damage in the first year was moderate, 68 (14 to 345), or high, 144 (20 to 1045).

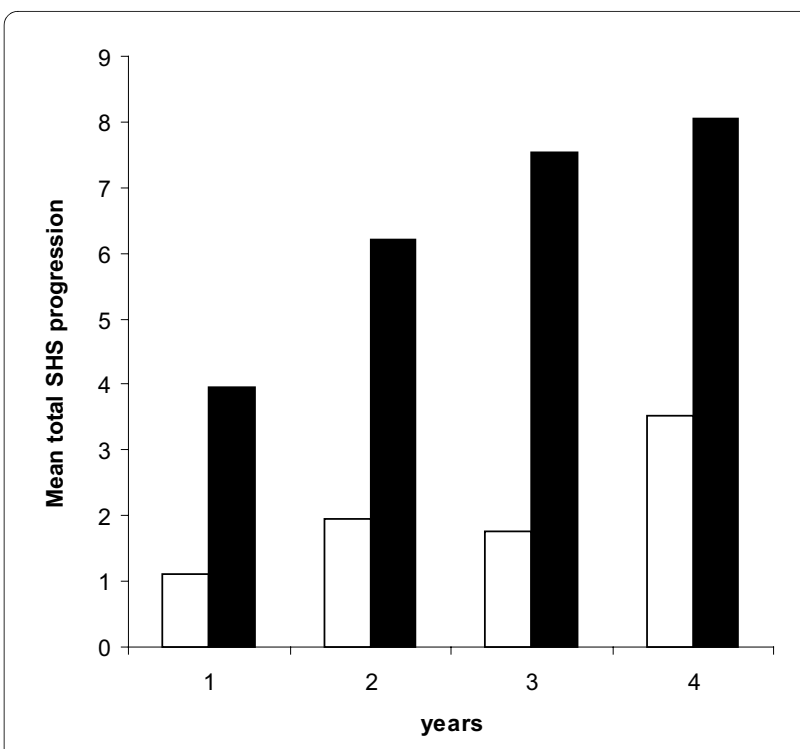

Figure 2 Mean progression of total Sharp-van der Heijde (SHS) in hands and feet after up to four years in patients with (black columns) and without (white columns) hand bone mineral density (BMD) loss in the first year of rheumatoid arthritis. The differences in mean total SHS progression after one, two, three and four years between patients with and without hand BMD loss in the first year are all significant $(P<0.05$ derived by non-parametric tests).

\section{Discussion}

This study into the association between hand BMD loss and radiographic joint damage progression shows that in the first year of RA hand BMD loss is associated with progressive joint damage in hands and feet, and that the association seems stronger with damage in hands than in feet. Moreover, hand BMD loss in the first year predicts subsequent progressive total joint damage: however, not independent of progressive joint damage in the first year.

The relation between BMD loss and progressive joint damage in the first year of RA suggests that both types of bone damage share common pathways in their pathogenesis and are the result of the same inflammatory process. It is thought that BMD loss in RA patients is caused, just like joint damage, by increased osteoclast activation, mainly regulated by TNF- $\alpha$, IL- 1 , IL-6, IL-17 and RANKL $[2,3]$. This is also in line with in vitro studies showing increased osteoclast functional activity in RA patients with generalized osteopenia [5]. A stronger association between hand BMD loss and progressive joint damage in hands compared with damage in feet also suggests that bones in the direct proximity of the inflammatory activity are more susceptible to BMD loss due to, besides the systemic, the local effect of high pro-inflammatory cytokine levels originating in adjacent active arthritis of the hand joints. On the other hand, it may also be partially explained by methodological issues. Firstly, less joint damage in feet can be detected due to less evaluated 
Table 2: Baseline and one-year follow-up predictors of subsequent progressive total joint damage in hands and feet after four years derived from univariate logistic regression analyses

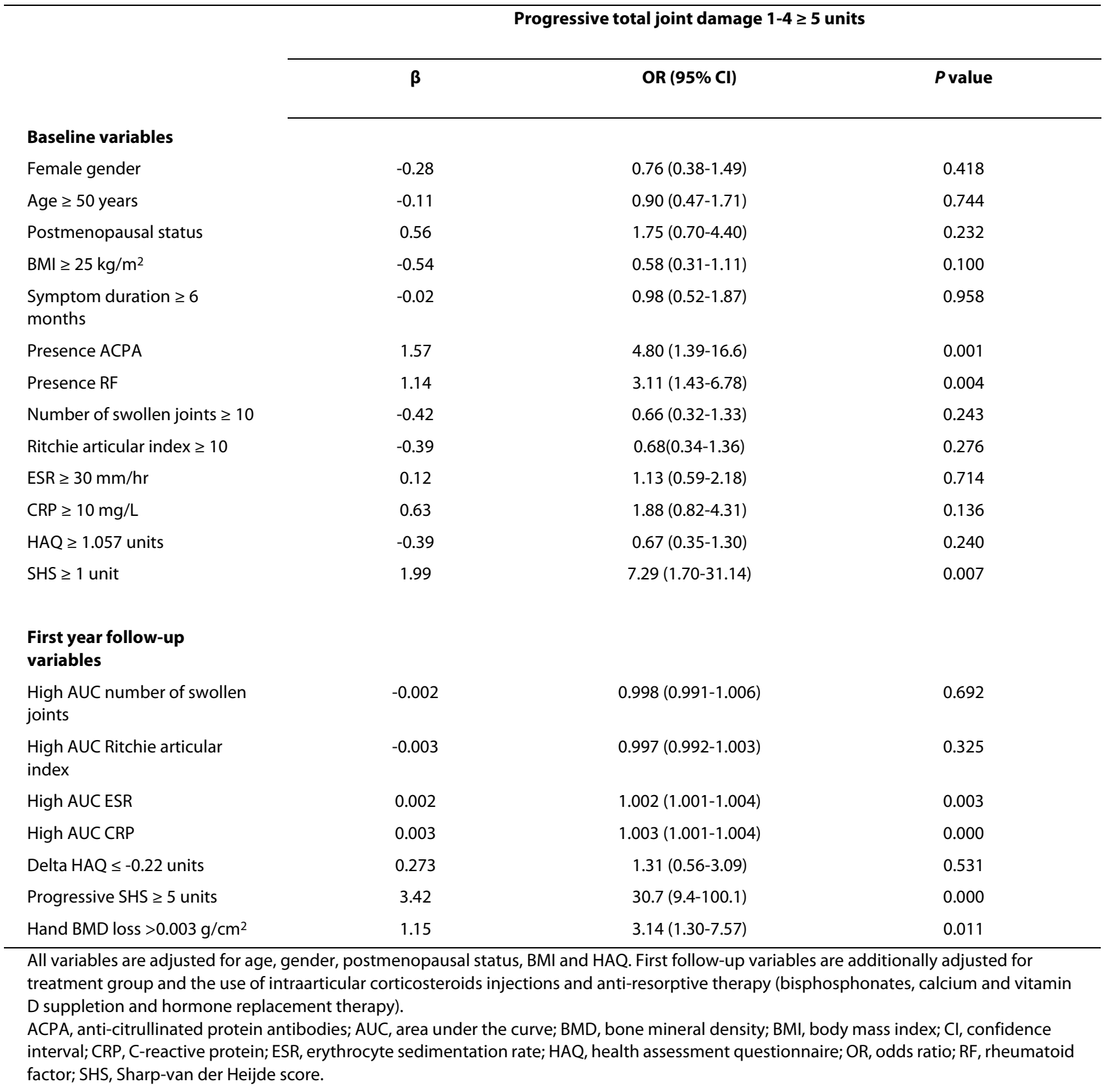

joints in feet than in hands. To limit this problem, we used a lower cut-off point to define progressive damage in feet ( 3 units in feet versus 5 units in hands due to 0.6 times lower maximum score in feet) and after this correction the percentages of patients having progressive joint damage in the hands and in feet were similar. Secondly, the patients in this subanalysis had significant less damage in the feet than the patients who were excluded from this subanalysis; however, in absolute terms, our popula- tion had active disease with high DAS and erosions present in the majority of patients at baseline.

In the first year of RA, hand BMD loss was seen in $68 \%$ of the patients, whereas progressive joint damage was seen in only $18 \%$. There are several explanations for this disassociation. First, localized BMD loss occurs mostly earlier in and more often during the disease course than advanced joint damage to bone and cartilage, especially in recent-onset RA $[9,10]$. This is emphasized by the sen- 
Table 3: Baseline and one-year follow-up predictors of subsequent progressive total joint damage in hands and feet after four years derived from multivariate logistic regression analysis

\begin{tabular}{|c|c|c|c|}
\hline \multirow[b]{3}{*}{ Baseline variables } & \multicolumn{3}{|c|}{ Progressive total joint damage $1-4 \geq 5$ units } \\
\hline & \multirow[t]{2}{*}{$\beta$} & \multirow[t]{2}{*}{ OR $(95 \% \mathrm{Cl})$} & \multirow[t]{2}{*}{$P$ value } \\
\hline & & & \\
\hline Presence ACPA & 1.20 & $3.14(1.37-6.12)$ & 0.015 \\
\hline Presence RF & 0.59 & $1.80(0.55-6.08)$ & 0.314 \\
\hline $\mathrm{SHS} \geq 1$ unit & 0.85 & $2.55(0.48-13.0)$ & 0.342 \\
\hline \multicolumn{4}{|l|}{$\begin{array}{l}\text { First year follow-up } \\
\text { variables }\end{array}$} \\
\hline High AUC ESR & 0.001 & $1.001(0.998-1.004)$ & 0.444 \\
\hline High AUC CRP & 0.001 & $1.001(0.999-1.004)$ & 0.339 \\
\hline Progressive SHS $\geq 5$ units & 3.35 & $27.1(10.9-67.4)$ & 0.000 \\
\hline Hand BMD loss $>0.003 \mathrm{~g} / \mathrm{cm}^{2}$ & 0.30 & $1.30(0.38-3.84)$ & 0.688 \\
\hline $\mathrm{R}^{2}$, adjusted & \multicolumn{3}{|c|}{0.534} \\
\hline
\end{tabular}

sitivity, specificity and predictive value of hand BMD loss with regard to progressive joint damage in the first year. Both the sensitivity and negative predictive value were high, $87 \%$ and $93 \%$, respectively, whereas the specificity and positive predictive value were low, $36 \%$ and $23 \%$, respectively, suggesting that most patients with progressive joint damage also have hand BMD loss at the same time, whereas in most patients with hand BMD loss progressive joint damage is absent. A second explanation might be that the technique of measurement of BMD loss by DXR is more sensitive to detect significant changes in cortical BMD during a follow-up period, while progressive joint damage as measured by the semi-objective SHS method is less sensitive to detect significant changes in structural damage, both erosions and JSN, during the same follow-up period.

We showed that hand BMD loss in the first year of RA is a predictor of subsequent progressive total joint damage, independent of the presence of auto-antibodies and joint damage at baseline. This is in accordance with the findings of Hoff and colleagues, who in RA patients with mean disease duration of 2.2 years at inclusion also showed that hand BMD loss was a predictor of progressive damage in hands after 5 and 10 years, independent of baseline predictors, such as joint damage at baseline and the presence of ACPA [24]. However, hand BMD loss is probably predicting progressive joint damage because hand BMD loss itself incorporates the effect of inflammation over time, as opposed to other factors that are static measures of the situation at baseline. Therefore we compared the predictive value of hand BMD loss with changes in other potential one-year follow-up predictors in multivariate regression analyses, and found that radiographic progressive joint damage is a much stronger predictor for subsequent progressive damage and that hand BMD loss was not predicting subsequent progressive damage independent of progressive damage in the first year probably due to the common inflammatory pathway between BMD loss and joint damage.

As progressive joint damage in the first year is superior as a predictor of further joint damage progression, in daily practice hand BMD loss after one year will not add to the identification of patients at risk for further destruction in recent-onset active RA. However, as hand BMD measurements by DXR are highly precise in detecting changes [12], early BMD evaluation, at three to four months after disease onset or even in the undifferentiated stage of the disease, might be a useful tool to predict poor outcome in these patients.

It might be argued whether progression of SHS is useful in clinical practice as a predictor, because it is a complicated scoring method that requires special training to perform. To mimic the daily clinical practice of radiographic assessment, we categorized the progression of 
Table 4: Baseline and one-year follow-up predictors, progressive SHS of 5 units or more in the first year excluded, of subsequent progressive total joint damage in hands and feet after four years derived from multivariate logistic regression analysis

\begin{tabular}{|c|c|c|c|}
\hline \multirow[b]{3}{*}{ Baseline variables } & \multicolumn{3}{|c|}{ Progressive joint damage $1-4 \geq 5$ units } \\
\hline & \multirow[t]{2}{*}{$\beta$} & \multirow[t]{2}{*}{ OR $(95 \% \mathrm{Cl})$} & \multirow[t]{2}{*}{$P$ value } \\
\hline & & & \\
\hline Presence ACPA & 1.30 & $3.95(1.17-15.0)$ & 0.017 \\
\hline Presence RF & 0.11 & $1.10(0.38-2.98)$ & 0.803 \\
\hline SHS $\geq 1$ unit & 1.81 & $5.78(1.23-28.1)$ & 0.020 \\
\hline \multicolumn{4}{|l|}{$\begin{array}{l}\text { First year follow-up } \\
\text { variables }\end{array}$} \\
\hline High AUC ESR & 0.002 & $1.002(0.999-1.004)$ & 0.160 \\
\hline High AUC CRP & 0.002 & $1.002(1.000-1.004)$ & 0.059 \\
\hline Progressive SHS $\geq 5$ units & - & - & - \\
\hline Hand BMD loss $>0.003 \mathrm{~g} / \mathrm{cm}^{2}$ & 1.10 & $3.00(1.12-8.81)$ & 0.035 \\
\hline $\mathrm{R}^{2}$, adjusted & & 0.290 & \\
\hline \multicolumn{4}{|c|}{$\begin{array}{l}\text { All variables with a } P<0.10 \text { in the univariate analyses, except progression SHS of } 5 \text { units or more in the first year, were entered in this } \\
\text { multivariate analysis corrected for age, gender, postmenopausal status, BMI and health assessment questionnaire and first year follow-up } \\
\text { variables additionally corrected for the use of anti-resorptive therapy (bisphosphonates, calcium and vitamin D suppletion and hormone } \\
\text { replacement therapy) and intraarticular corticosteroid injections during first year and treatment group during. } \\
\text { ACPA, anti-citrullinated protein antibodies; AUC, area under the curve; BMD, bone mineral density; BMl, body mass index; Cl, confidence } \\
\text { interval; CRP, C-reactive protein; ESR, erythrocyte sedimentation rate; OR, odds ratio; RF, rheumatoid factor; SHS, Sharp-van der Heijde scol }\end{array}$} \\
\hline
\end{tabular}

joint damage in four categories: patients with no, dubious, moderate or high progression. We found that even patients with dubious progressive damage in the first year had 5-fold more subsequent progressive damage, and with moderate and high progression even 65-fold and 138-fold more than patients with no progression, while hand BMD loss was associated with 3 -fold more subsequent damage. Furthermore hand BMD loss measured by the DXR technology also requires special equipment, in general not available in medical centers, or payments for the measurements when the online service is used.

Further the fact that there are significant differences in baseline variables between patients who were included in this trial and patients who were not included might be argued. The included patients have shorter disease duration, are less often ACPA positive and have less joint damage at baseline, suggesting that patients with relatively less active disease were included in this trial. Nevertheless, in absolute terms, the included patients had high disease activity with erosive damage in the majority, even in this early stage of the disease.

\section{Conclusions}

In the first year of RA, accelerated hand BMD loss is associated with progressive joint damage in both hands and feet. Hand BMD loss in the first year is a predictor of sub- sequent progressive total joint damage; however, it is not independent of progressive joint damage in the first year, which remains the strongest predictor of subsequent damage. These findings suggest that both methods detect effects in a common pathway of osteoclastic activity and that initial joint damage progression in the first year of RA is superior in predicting later progressive joint damage.

\section{Abbreviations}

ACPA: anti-citrullinated protein antibodies; ACR: American College of Rheumatology; AUC: area under the curve; BMD: bone mineral density; BMI: body mass index; $\mathrm{Cl}$ : confidence interval; CRP: C-reactive protein; DAS: disease activity score; DEXA: dual energy X-ray absorptiometry; DMARDs: disease modifying anti-rheumatic drugs; DXR: digital X-ray radiogrammetry; ESR: erythrocyte sedimentation rate; HAQ: health assessment questionnaire; HRT: hormone replacement therapy; IL: interleukin; IQR: interquartile range; JSN: joint space narrowing; MTX: methotrexate; OR: odds ratio; RA: rheumatoid arthritis; RAI: ritchie articular index; RANKL: receptor activator of nuclear factor kappa B ligand; RF: rheumatoid factor; SD: standard deviation; SHS: Sharp-van der Heijde score; TNF-a: tumor necrosis factor alpha; VAS: visual analogue score.

\section{Competing interests}

CF Allaart received lecture fees from Schering-Plough. BAC Dijkmans has received funds for research and lecture fees from Schering-Plough.

\section{Authors' contributions}

MG-Y, YPMG-R, JKdV-B, WJH, BACD, CFA and WFL contributed to study design. MG-Y, NBK, YPMG-R, JKdV-B, SMvdK, WJH, BACD and CFA contributed to study coordination. MG-Y, NBK, YPMG-R, JKdV-B, SMvdK, AHG, HKR, WJH, BACD, CFA and WFL contributed to acquisition of data. MG-Y contributed to statistical analysis. MG-Y, WJH, BACD, CFA, and WFL contributed to analysis and interpre- 
tation of data. MG-Y, WJH, BACD, CFA and WFL contributed to manuscript preparation. All authors read and approved the final manuscript.

\section{Acknowledgements}

We would like to thank all patients as well as the following rheumatologists, other than the authors, who participated in the Foundation for Applied Rheumatology Research (all locations are in The Netherlands): C. Bijkerk, MD (Reinier de Graaf Gasthuis, Delft); W.M. de Beus, MD (Medical Center Haaglanden, the Hague); M.H.W. de Bois (Medical Center Haaglanden, The Hague); F.C. Breedveld (Leiden University Medical Center, Leiden); G. Collée, MD (Medical Center Haaglanden, The Hague); J.A.P.M. Ewals, MD (Haga Hospital, The Hague); J.B.A.M. Grillet, MD (De Honte Hospital, Terneuzen); J.H.L.M. van Groenendael (Franciscus Hospital, Roosendaal); K.H. Han, MD (Medical Center RijnmondZuid); J.M.W. Hazes, MD (Erasmus Medical Center, Rotterdam); H.M.J. Hulsmans, MD (Haga Hospital, The Hague); M.H. de Jager, MD (Albert Schweitzer Hospital, Dordrecht); J.M. de Jonge-Bok, MD (retired); P.J.S.M. Kerstens, MD (Jan van Breemen Institute, Amsterdam); M.V. van Krugten, MD (Walcheren Hospital, Vlissingen); H. van der Leeden, MD (retired); M.F. van Lieshout-Zuidema, MD (Spaarne Hospital, Hoofddorp); A. Linssen, MD (Kennemer Gasthuis, Haarlem); P.A.H.M. van der Lubbe, MD (Vlietland Hospital, Schiedam); C. Mallée (Kennemer Gasthuis, Haarlem); E.T.H. Molenaar, MD (Groene Hart Hospital, Gouda); H.C. van Paassen, MD (Sint Franciscus Gasthuis, Rotterdam); H.K. Markusse, MD (deceased); A.J. Peeters, MD (Reinier de Graaf Hospital, Delft); D. van Schaardenburg, MD (VU Medical Center, Amsterdam and Jan van Breemen Institute, Amsterdam); P.E.H. Seys, MD (Lievensberg Hospital, Bergen op Zoom); R.M. van Soesbergen, MD (retired); P.B.J. de Sonnaville, MD (Oosterschelde Hospital, Goes); I. Speyer, MD (Bronovo Hospital, The Hague); K.S.S. Steen, MD (Kennemer Gasthuis, Haarlem); J.Ph. Terwiel, MD (Spaarne Hospital, Hoofddorp); A.E. Voskuyl, MD (VU Medical Center, Amsterdam); M.L. Westedt, MD (Bronovo Hospital, The Hague); S. ten Wolde, MD (Kennemer Gasthuis, Haarlem); J.M.G.W. Wouters, MD (Sint Franciscus Gasthuis, Rotterdam); D. van Zeben, MD (Sint Franciscus Gasthuis, Rotterdam). We would also like to thank all other rheumatologists and trainee rheumatologists who enrolled patients in this study, all research nurses for their contributions and the Sectra company for estimating BMD of the metacarpals by online digital $\mathrm{X}$-ray radiogrammetry.

This study was funded by a grant of the Dutch College of Health Insurances (College Voor Zorgverzekeringen) with additional funding provided by Schering-Plough, B.V. and Centocor, Inc. The authors, not the sponsors, were responsible for the study design, the collection, analyses and interpretation of data, the writing of this article and the decision to publish.

\section{Author Details}

1Department of Rheumatology, Leiden University Medical Center, Albinusdreef 2, 2333 ZA, Leiden, The Netherlands, ${ }^{2}$ Department of Rheumatology, VU Medical Center, De Boelelaan 1109, 1007 MB Amsterdam, The Netherlands, ${ }^{3}$ Department of Rheumatology, Vlietland Hospital, Burgemeester Knappertlaan 25, 3116 BA Schiedam, The Netherlands, ${ }^{4}$ Haga Hospital, Leyweg 275, $2545 \mathrm{CH}$ The Hague, The Netherlands and 5 Department of Rheumatology, Jan van Breemen Institute, Dr Jan van Breemenstraat 2, 1056 AB Amsterdam, The Netherlands

\section{Received: 12 October 2009 Revised: 16 March 2010}

Accepted: 20 May 2010 Published: 20 May 2010

\section{References}

1. Gravallese EM: Bone destruction in arthritis. Ann Rheum Dis 2002, 61 Suppl 2:ii84-ii86.

2. Schett G: Review: Immune cells and mediators of inflammatory arthritis. Autoimmunity 2008, 41:224-2229.

3. O'Gradaigh D, Ireland D, Compston JE: Joint erosion in rheumatoid arthritis: interactions between tumour necrosis factor alpha, interleukin 1, and receptor activator of nuclear factor kappaB ligand (RANKL) regulate osteoclasts. Ann Rheum Dis 2004, 63:354-359.

4. Ainola MM, Mandelin JA, Liljestrom MP, Li T-F, Hukkanen MVJ, Konttinen YT: Pannus invasion and cartilage degradation in rheumatoid arthritis: Involvement of MMP-3 and interleukin-1 $\beta$. Clin Exp Rheumatol 2005, 23:644-650

5. Hirayama T, Danks L, Sabokhar A, Athanasou NA: Osteoclast formation and activity in the pathogenesis of osteoporosis in rheumatoid arthritis. Rheumatology (Oxford) 2003, 42:1429-1430.
6. Güler-Yüksel M, Allaart CF, Goekoop-Ruiterman YP, deVries-Bouwstra JK, van Groenendael JH, Mallée C, de Bois MH, Breedveld FC, Dijkmans BA, Lems WF: Changes in hand and generalized bone mineral density in patients with recent-onset rheumatoid arthritis. Ann Rheum Dis 2009, 68:330-336

7. Deodhar AA, Brabyn J, Pande I, Scott DL, Woolf AD: Hand bone densitometry in rheumatoid arthritis, a five year longitudinal study: an outcome measure and a prognostic marker. Ann Rheum Dis 2003, 62:767-770.

8. Haugeberg G, Green MJ, Quinn MA, Marzo-Ortega H, Proudman S, Karim Z, Wakefield RJ, Conaghan PG, Stewart S, Emery P: Hand bone loss in early undifferentiated arthritis: evaluating bone mineral density loss before the development of rheumatoid arthritis. Ann Rheum Dis 2006, 65:736-740

9. Brook A, Corbett M: Radiographic changes in earlyrheumatoid disease. Ann Rheum Dis 1977, 36:71-73.

10. Devlin J, Lilley J, Gough A, Huissoon A, Holder R, Reece R, Perkins P, Emery $P$ : Clinical associations of dual-energy $X$-ray absorptiometry measurement of hand bone mass in rheumatoid arthritis. $\mathrm{Br} J$ Rheumatol 1996, 35:1256-1262.

11. Rosholm A, Hyldstrup L, Baeksgaard L, Grunkin M, Thodberg HH: Estimation of bone mineral density by Digital X-ray Radiogrammetry. Theoretical background and clinical testing. Osteoporos Int 2001, 12:961-969.

12. Elliot JR, Fenton AJ, Young T, Mansfield A, Burton C, Wilkinson TJ: The precision of digital X-ray radiogrammetry compared with DXA in subjects with normal bone density or osteoporosis. $J$ Clin Densitom 2005, 8:187-190.

13. Böttcher J, Pfeil A, Rosholm A, Soros P, Petrovitch A, Schaefer ML, Seidl BE, Malich A, Hansch A, Wolf G, Kaiser WA: Computerized quantification of joint space narrowing and periarticular demineralization in patients with rheumatoid arthritis based on digital x-ray radiogrammetry. Invest Radiol 2006, 41:36-44.

14. Hoff M, Haugeberg G, Kvien TK: Hand bone loss as an outcome measure in established rheumatoid arthritis: 2-year observational study comparing cortical and total bone loss. Arthritis Res Ther 2007, 9:R81.

15. Jawaid WB, Crosbie D, Shotton J, Reid DM, Stewart A: Use of digital $x$ ray radiogrammetry in the assessment of joint damage in rheumatoid arthritis. Ann Rheum Dis 2006, 65:459-464.

16. Haugeberg G, Lodder MC, Lems WF, Uhlig T, Ørstavik RE, Dijkmans BA, Kvien TK, Woolf AD: Hand cortical bone mass and its associations with radiographic joint damage and fractures in 50-70 year old female patients with rheumatoid arthritis: cross sectional Oslo-TruroAmsterdam (OSTRA) collaborative study. Ann Rheum Dis 2004, 63:1331-1334.

17. Jensen T, Klarlund M, Hansen M, Jensen KE, Pødenphant J, Hansen TM, Skjødt H, Hyldstrup L, TIRA Group: Bone loss in unclassified polyarthritis and early rheumatoid arthritis is better detected by digital $x$ ray radiogrammetry than dual $\mathrm{x}$ ray absorptiometry: relationship with disease activity and radiographic outcome. Ann Rheum Dis 2004, 63:15-22.

18. Jensen T, Hansen M, Jensen KE, Pødenphant J, Hansen TM, Hyldstrup L: Comparison of dual X-ray absorptiometry (DXA), digital X-ray radiogrammetry (DXR), and conventional radiographs in the evaluation of osteoporosis and bone erosions in patients with rheumatoid arthritis. Scand J Rheumatol 2005, 34:27-33.

19. Böttcher J, Pfeil A, Rosholm A, Petrovitch A, Seidl BE, Malich A, Hansch A, Wolf G, Kaiser WA: Digital X-ray radiogrammetry combined with semiautomated analysis of joint space widths as a new diagnostic approach in rheumatoid arthritis: a cross-sectional and longitudinal study. Arthritis Rheum 2005, 52:3850-3859.

20. Böttcher J, Pfeil A, Mentzel H, Kramer A, Schäfer ML, Lehmann G, Eidner T, Petrovitch A, Malich A, Hein G, Kaiser WA: Peripheral bone status in rheumatoid arthritis evaluated by digital $\mathrm{X}$-ray radiogrammetry and compared with multisite quantitative ultrasound. Calcif Tissue Int 2006, 78:25-34.

21. Böttcher J, Malich A, Pfeil A, Petrovitch A, Lehmann G, Heyne JP, Hein G, Kaiser WA: Potential clinical relevance of digital radiogrammetry for quantification of periarticular bone demineralization in patients suffering from rheumatoid arthritis depending on severity and compared withDXA. Eur Radiol 2004, 14:631-637. 
22. Böttcher J, Pfeil A, Rosholm A, Schäfer ML, Malich A, Petrovitch A, Seidl B, Lehmann G, Mentzel HJ, Hein G, Wolf G, Kaiser WA: Computerized digital imaging techniques provided by digital $\mathrm{X}$-ray radiogrammetry as new diagnostic tool in rheumatoid arthritis. J Digit Imaging 2006, 19:279-288.

23. Stewart A, Mackenzie LM, Black AJ, Reid DM: Predicting erosive disease in rheumatoid arthritis. A longitudinal study of changes in bone density using digital $\mathrm{X}$-ray radiogrammetry: a pilot study. Rheumatology 2004, 43:1561-1564.

24. Hoff M, Haugeberg G, Odegard S, Syversen S, Landewé R, Heijde D van der, Kvien TK: Cortical hand bone loss after 1 year in early rheumatoid arthritis predicts radiographic hand joint damage at 5-year and 10year follow-up. Ann Rheum Dis 2009, 68:324-329.

25. Goekoop-Ruiterman YP, de Vries-Bouwstra JK, Allaart CF, van Zeben D, Kerstens PJ, Hazes JM, Zwinderman AH, Peeters AJ, de Jonge-Bok JM, Mallée C, de Beus WM, de Sonnaville PB, Ewals JA, Breedveld FC, Dijkmans BA: Comparison of treatment strategies in early rheumatoid arthritis: a randomized trial. Ann Intern Med 2007, 146:406-415.

26. Barnett $E$, Nordin BE: The radiological diagnosis of osteoporosis: a new approach. Clin Radiol 1960, 11:166-174.

27. van der Heijde D: How to read radiographs according to the Sharp/van der Heijde method. J Rheumatol 1999, 26:743-745.

28. Rönnelid J, Wick MC, Lampa J, Lindblad S, Nordmark B, Klareskog L, van Vollenhoven RF: Longitudinal analysis of citrullinated protein/peptide antibodies (anti-CP during 5 year follow up in early rheumatoid arthritis: anti-CP status predicts worse disease activity and greater radiological progression. Ann Rheum Dis 2005, 64:1744-1749.

29. Wolfe F: A reappraisal of HAQ disability in rheumatoid arthritis. Arthritis Rheum 2000, 43:2751-2761.

30. Wells GA, Tugwell P, Kraag GR, Baker PR, Groh J, Redelmeier DA: Minimum important difference between patients with rheumatoid arthritis: the patient's perspective. J Rheumatol 1993, 20:557-560.

doi: 10.1186/ar3025

Cite this article as: Güler-Yüksel et al., Accelerated hand bone mineral density loss is associated with progressive joint damage in hands and feet in recent-onset rheumatoid arthritis Arthritis Research \& Therapy 2010, 12:R96

Submit your next manuscript to BioMed Central and take full advantage of:

- Convenient online submission

- Thorough peer review

- No space constraints or color figure charges

- Immediate publication on acceptance

- Inclusion in PubMed, CAS, Scopus and Google Scholar

- Research which is freely available for redistribution

Submit your manuscript at www.biomedcentral.com/submit
Ciomed Central 